\title{
FORMAÇÃO DO BIBLIOTECÁRIO E AS HABILIDADES E COMPETÊNCIAS REQUERIDAS EM CONCURSOS PÚBLICOS NO ESTADO DO PARANÁ
}

\section{LIBRARY TRAINING AND SKILLS REQUIRED IN PUBLIC TENDERS IN THE STATE OF PARANÁ}

João Arlindo dos Santos Neto

Universidade Estadual de Londrina Brasil

Carolina Rezende de Oliveira

Universidade Estadual de Londrina Brasil

Submetido em: 30/09/2019

Aceito em: 09/07/2020

Publicado em: 12/08/2020

Licença:

(c) (i) (9)

Autor para correspondência: João Arlindo dos Santos Neto

Email: santosneto@uel.br

ORCID: https://orcid.org/0000-0003-1833-911X

Como citar este artigo:

SANTOS NETO, João Arlindo; OLIVEIRA, Carolina Rezende. Formação do bibliotecário e as habilidades e competências requeridas em concursos públicos no estado do Paraná. REBECIN, São Paulo, v. 6, n. 2, p. 21-41, jul./dez. 2019. 


\title{
RESUMO
}

Discute a formação do bibliotecário frente à demanda apresentada pelo mundo do trabalho no estado do Paraná, em especial, pelos requisitos solicitados em concursos públicos. 0 objetivo geral foi analisar as habilidades e competências requeridas à atuação do bibliotecário no estado do Paraná, e como objetivos específicos buscou verificar quais são as habilidades dos egressos formados a partir da matriz curricular de 2014 do curso de Biblioteconomia da Universidade Estadual de Londrina; identificar a remuneração e quais são as habilidades requeridas pelas bibliotecas das universidades estaduais constantes nos editais. $O$ corpus da pesquisa foi constituído pelos editais de concursos das seis universidades estaduais do Paraná e pela matriz curricular do ano de 2014 do curso de Biblioteconomia da UEL. A pesquisa é de natureza básica, do tipo exploratória e tem como método a pesquisa documental. Os dados foram analisados utilizando-se a análise categorial de dados, influenciada pela análise de conteúdo. Como resultados, identifica similaridade entre os editais de concurso para bibliotecário tanto nas competências e habilidades gerais quanto nas mais detalhadas. Conclui que após a comparação da matriz curricular dos egressos do curso de Biblioteconomia da UEL com os requisitos exigidos pelos editais de concurso para contratação de bibliotecários das seis universidades estaduais do Paraná, a formação dos egressos atende aos requisitos exigidos.

Palavras-Chave: Competências e Habilidades do bibliotecário. Concurso para bibliotecário. Formação do bibliotecário. Mundo do trabalho. Universidades Estaduais do Paraná.

\begin{abstract}
It discusses the education of the librarian in face of the demand presented by the world of work in the state of Paraná, in particular, by the requirements requested in public tenders. The general objective was to analyze the skills and competencies required by the librarian in the state of Paraná, and as specific objectives sought to verify the skills of the graduates from the 2014 Curriculum Matrix of the University of Londrina Library; identify the compensation and what are the skills required by state university libraries in the edicts. The corpus of the research was constituted by the public notices of competitions of the six state universities of Paraná and by the curricular matrix of the year 2014 of the course of Library of UEL. The research is basic, exploratory in nature and has as its method documentary research. Data were analyzed using categorical data analysis, influenced by content analysis. As a result, it identifies similarity between librarian contest notices in both general and more detailed competencies and skills. It concludes that after comparing the curriculum matrix of the graduates of the UEL Librarianship course with the requirements required by the bidding procedures for hiring librarians from the six state universities of Paraná, the graduation training meets the required requirements.
\end{abstract}

Keywords: Librarian Skills and Abilities. Librarian Contest. Librarian training. World of work. State Universities of Paraná.

\section{INTRODUÇÃO}

Os avanços tecnológicos proporcionam a efetivação de equipamentos e suportes que facilitam o desenvolvimento do trabalho do bibliotecário. Esta evolução é evidente, dando espaço para o bibliotecário progredir e também se aprimorar 
profissionalmente, pois quem trabalha com a informação tem o campo de atuação ampliado. O mundo do trabalho está exigindo mais dos profissionais, por isso a importância do bibliotecário sempre se atualizar, aprimorando suas habilidades e desenvolvendo diversas competências.

A tecnologia facilita e torna o trabalho do bibliotecário mais produtivo, satisfazendo parcialmente as necessidades informacionais dos usuários de maneira rápida e momentânea. Para atender as demandas informacionais, esse profissional precisa desenvolver competências e habilidades durante sua formação, na graduação, mas também, após ela, na formação continuada.

É possível identificar na literatura da área de Ciência da Informação $(\mathrm{Cl})$ e Biblioteconomia dados sobre o perfil, a formação e as possibilidades de formação do bibliotecário exigidas pelo mundo do trabalho. Existem autores que descrevem as diversas funções que o bibliotecário pode ter em diferentes ambientes de trabalho, outros que relacionam quais habilidades e competências são necessárias a determinados campos de atuação, entre outros. No entanto, o foco deste artigo não é discutir tais aspectos ou estabelecer requisitos para que o bibliotecário possa atuar em universidades, mas contrapor as habilidades e competências frente aos conteúdos curriculares do curso de graduação em Biblioteconomia.

Deste modo, este artigo procurou analisar as competências e habilidades dos egressos formados a partir da matriz curricular de 2014 do curso de Biblioteconomia de uma universidade paranaense, comparando-as com as exigências do mundo do trabalho atual, em especial aquelas requeridas nos concursos para o cargo de bibliotecário nas universidades estaduais do Paraná. O presente artigo é fruto de uma pesquisa em nível de graduação, resultado do trabalho de conclusão de curso de Oliveira (2015). Este artigo, portanto, apresenta dados e resultados atualizados que complementam a referida pesquisa, com resultados e discussões reformuladas.

\section{A PROFISSÃO "BIBLIOTECÁRIO" FRENTE AO MUNDO DO TRABALHO: BREVES DIÁLOGOS}

No Brasil, a profissionalização em Biblioteconomia é conquistada com a obtenção de um diploma em nível de graduação, através do bacharelado. Os registros profissionais dos egressos de cursos universitários são obtidos com a apresentação do diploma e outras formalidades, junto ao Conselho Regional da área de formação, 
adquirindo, assim, a habilitação para o exercício da profissão, caso esta esteja regulamentada, como é o caso do bibliotecário amparado pela Lei 4.084 de 1962 (MIRANDA, 2003).

A profissão de bibliotecário, em alguns casos, é estereotipada como limitada e monótona. Aos membros da comunidade bibliotecária é fato que isto não condiz com a realidade da profissão. No entanto, para a sociedade em geral, até mesmo entre conhecidos de algum profissional, é a imagem que se tem. Reforçando o exposto, em muitos contextos sociais, a educação, a informação e a cultura não são prioridades e, com isso, infelizmente a existência dos bibliotecários/bibliotecas, dentre outros espaços e profissionais, ainda não é realidade ou é incipiente.

Corrobora-se com Silveira (2011) que "O bibliotecário, quando disposto e preparado para exercer bem os seus diversos papéis, incluindo o de agente de mudança social, deve integrar as funções da biblioteca e da informação às demais ações vitais da sociedade." Assim, o profissional deixa evidente sua importância naquele contexto e contribui para que sua imagem perante a sociedade seja (re)formulada.

A atividade do bibliotecário é voltada para a informação e principalmente para a mediação dela. Por serem a $\mathrm{Cl}$ e a Biblioteconomia áreas interdisciplinares, é necessário e essencial que o bibliotecário tenha uma educação continuada para seu desenvolvimento pessoal e profissional e para o aperfeiçoamento e atualização de suas habilidades e competências.

Cada vez mais o mundo de trabalho está favorável ao bibliotecário, como comprova uma pesquisa de nível nacional que foi realizada em 2006, por Figueiredo e Souza (2007), com o foco de mapear o campo de atuação dos bibliotecários no mundo do trabalho. Os resultados mostraram que "[...] a taxa de empregabilidade da profissão é superior a 90\%, tendo como principal setor econômico de atuação o terciário (serviços), sendo as empresas privadas e públicas as principais empregadoras" (FIGUEIREDO; SOUZA, 2007, p. 29).

O campo de trabalho na área da Biblioteconomia é vasto e oferece diversas oportunidades para os bibliotecários, ainda que atualmente o cenário não esteja favorável. A esses profissionais são requeridas mudanças no perfil, ainda mais no que diz respeito à visão interdisciplinar, integrando as suas atividades tradicionais novas competências e habilidades para poder aproveitar as oportunidades e garantir sua 
competitividade no mundo de trabalho. Conti (2009, p.42) enfatiza que devido a "[...] globalização da economia e das tecnologias de informação e comunicação, esse profissional precisa estar preparado para ser competitivo nesse novo contexto."

Ao profissional da informação é requerida uma formação voltada para atender a uma determinada demanda social, levando em conta que apenas a formação base não é a solução; para que este profissional ocupe seu espaço no mundo de trabalho, é importante que a formação defina um perfil de profissional que se deseja e que haja também ações que divulguem o profissional para o mercado empregador (VALENTIM, 2002).

As profissões de uma maneira geral passam por uma reorganização de seus componentes/fazeres, com isso surgem novas situações que possibilitam interdependência, competição e modificações nas práticas educacionais ao formar novos profissionais. A formação de profissionais deveria ser pensada além de sua formação específica, a expectativa é que eles continuem na pesquisa e participem de congressos, sempre atentos aos avanços tecnológicos e seus novos instrumentos, que desenvolvam capacidade de gerência em diversas circunstâncias e diferentes níveis, que saibam trabalhar em equipe, inclusive com colegas de especialidades diferentes e mesmo com profissionais de outras áreas do conhecimento, que não as suas (BARBOSA, 2014). Esse discurso vai ao encontro do que é presente na área da $\mathrm{Cl}$ e Biblioteconomia, onde o bibliotecário deve se preocupar sempre em se atualizar para melhor se adequar ao mundo de trabalho.

Com o avanço tecnológico esse profissional pode atuar em: bibliotecas públicas, comunitárias, escolares, infantis, universitárias, especializadas, especiais, ambulantes, itinerantes, alternativas; centros de documentação, de análise da informação, de restauração de obras, de pesquisa; jornais e revistas; videotecas, rádio e televisão; livrarias e sebos; museus; bancos; órgãos públicos (Legislativo, Executivo e Judiciário), empresas privadas (indústrias em geral/segmentos econômicos como editoras, base de dados etc.); redes sociais; agências de publicidade; centros culturais; brinquedotecas e ludotecas; editoras; escritórios de advocacia e cartórios; pinacotecas; arquivos públicos e pessoais; sindicatos; associações; organização não governamentais; Instituições de Ensino Superior (públicas e privadas); organizações; laboratórios de pesquisa científica e tecnológica, dentre outros (BIBLIO EVENTOS, 2015; BRASIL, 2010; VALENTIM, 2002). 
No contexto desses diversos campos de atuação, existem alguns requisitos exigidos pelo mundo de trabalho. Nesta seção, apresentam-se àqueles indicados nas vagas disponíveis para o cargo de bibliotecário no estado do Paraná, independente do campo de atuação. Os requisitos mencionados adiante foram retirados do site InfoHome (2018), que disponibiliza uma aba chamada "mercado" e é atualizada semanalmente.

Como esperado, verificou-se que todos os requisitos pedem formação no curso de Biblioteconomia com registro nos Conselhos estaduais. Alguns, além da graduação e do registro, exigem também o título de mestrado e experiência na atuação como bibliotecário. Além dos quesitos voltados para a formação acadêmica e registro no Conselho, foram identificados no InfoHome (2018) as atribuições inerentes ao trabalho de bibliotecário e os requisitos específicos para ingresso no cargo, conforme se apresenta a seguir:

\section{a) atribuições inerentes ao trabalho de bibliotecário:}

$\checkmark$ acompanhar, orientar, capacitar, administrar, organizar e dirigir a equipe da biblioteca/centro de documentação/centro de informação quanto às normas e procedimentos internos, visando à padronização dos processos;

$\checkmark$ analisar os recursos e as necessidades de informação da comunidade em que está inserido;

$\checkmark$ atender aos estudantes, professores, colaboradores e demais usuários da biblioteca, disponibilizando as informações solicitadas, na qualidade e no tempo requerido, seja na localização das obras e publicações em geral, de acordo com o assunto requerido; auxiliar em consultas e pesquisas e, se necessário providenciar empréstimo entre Bibliotecas;

$\checkmark$ compilar bibliografias gerais ou específicas, utilizando processos manuais ou mecanizados;

$\checkmark$ controlar e zelar pela correta utilização dos materiais, equipamentos e bens públicos;

$\checkmark$ coordenar as atividades da biblioteca (física e digital), utilizando recursos bibliográficos, audiovisuais etc.;

$\checkmark$ difundir a importância da leitura e os benefícios do uso da informação;

$\checkmark$ disponibilizar e disseminar a informação em qualquer suporte, com o objetivo de facilitar o acesso, apropriação e construção do conhecimento;

$\checkmark$ elaborar projetos para melhoria dos serviços prestado; desenvolver estudos de usuário; realizar difusão cultural;

$\checkmark$ manter intercâmbio com as demais bibliotecas/centros de documentação/centros de informação;

$\checkmark$ ministrar treinamento em normalização e formatação do trabalho acadêmico, fontes e recursos de informação;

$\checkmark$ supervisionar e executar a classificação e a catalogação dos recursos bibliográficos e não bibliográficos de acordo com as normas de padrão internacional;

$\checkmark$ ser dinâmico, proativo, organizado, ético, empático e saber trabalhar em equipe;

b) requisitos específicos para ingresso no cargo:

$\checkmark$ assessorar trabalhos de pesquisa técnico-administrativa;

$\checkmark$ atuar como instrutor do software de automação da biblioteca; 
$\checkmark$ conhecer e dominar o sistema Pergamum, informática (pacote Office) e realizar pesquisas no Portal de Periódicos da Capes em língua inglesa;

$\checkmark$ elaborar relatório mensal/anual do setor, informando estatística das movimentações, consultas, devoluções efetuadas e analisar os resultados, para propor novos planejamentos, entre outras atividades;

$\checkmark$ formular e implementar políticas para o desenvolvimento de serviços da biblioteca;

$\checkmark$ fornecer dados estatísticos e apresentar relatórios de suas atividades;

$\checkmark$ planejar e coordenar a realização de eventos culturais na biblioteca, pesquisando e negociando parcerias;

$\checkmark$ planejar e executar a política de seleção e de aquisição de material bibliográfico e não bibliográfico;

$\checkmark$ promover medidas necessárias à conservação de documentos;

$\checkmark$ realizar o inventário anual de coleta de livros, de acordo com a listagem do acervo, visando a organização e o controle do mesmo;

$\checkmark$ solicitar International Standard Serial Number - ISSN e International Standard Book Number - ISBN para publicações;

$\checkmark$ ter experiência no recebimento de Comissões do Ministério da Educação (MEC) para avalição de cursos.

Verifica-se que muitas atribuições inerentes ao trabalho de bibliotecário e, também, diversos requisitos específicos para ingresso no cargo apresentados pelas vagas recuperadas; dificilmente haverá um bibliotecário com todas as competências e habilidades altamente desenvolvidas. No entanto, o intuito desta subseção foi reunir tais requisitos e verificar a diversidade deles, o que representa um desafio tanto para o estudante de Biblioteconomia (que precisa desenvolver tais aspectos) quanto para os cursos de graduação (que precisam inserir no total da carga horária do curso o maior número de disciplinas que possibilitam tais competências e habilidades).

Após identificar os requisitos presentes nos anúncios das vagas para o estado do Paraná no site InfoHome (que divulga vagas disponíveis em todo o território nacional), apresentam-se algumas pesquisas que também investigaram o cenário profissional, a formação do bibliotecário e os concursos na área.

Lima (2007) identificou o perfil dos profissionais da informação demandados pelo mercado de trabalho das regiões Sul e Sudeste do Brasil e constatou que as habilidades mais requeridas dos profissionais são as habilidades técnicas (que compreendem o uso de métodos específicos da área) e de tecnologias de informação. Além disso, considera que o mundo de trabalho não reconhece o profissional da informação como um profissional multidisciplinar com distintas habilidades, mas como um profissional técnico e restrito.

Campos (2008) investigou as características dos bibliotecários que trabalham em IES privadas em Brasília/DF e as expectativas dos empregadores em relação às 
características requeridas para os bibliotecários que são selecionados. Como resultados, apontou que as tarefas exercidas pelos bibliotecários ainda se referem exclusivamente a: aquisição, processamento e disseminação; e em menor ocorrência, gestão de processos, atendimento a pesquisas, elaboração de projetos e normalização.

Kautzmann (2010) analisou as competências exigidas nas ofertas de emprego para bibliotecários de bibliotecas universitárias e as comparou com a Classificação Brasileira de Ocupações. Identificou que as vagas, em sua maioria, requerem competências para tratar tecnicamente a informação e disponibilizá-la em qualquer suporte. A autora ressalta que "[...] habilidades e conhecimentos como 'desenvolver planos de divulgação e marketing', 'desenvolver políticas de informação' e 'elaborar políticas de funcionamento de unidades, redes e sistemas de informação' [...]" (KAUTZMANN, 2010, p. 45) mesmo sendo fundamentais para o funcionamento de bibliotecas universitárias, não foram encontradas nas ofertas de emprego analisadas.

Faria (2015) investigou os fatores que influenciam a inserção dos bibliotecários no mercado de trabalho e concluiu que além da formação acadêmica e das habilidades e competências técnicas, o mercado também espera que este profissional tenha desenvolvida as habilidades de comunicação. Moraes (2015) ao investigar como se apresenta o mercado de trabalho do bibliotecário na região Sul do Brasil, identificou que além dos conhecimentos técnicos, o mercado também exige características pessoais, psicológicas e emocionais determinadas. Além disso, em alguns casos, encontrou vagas que requereram conhecimento em informática, em bases de dados e softwares específicos.

Simões e Marquez (2015) pesquisaram os conteúdos da estrutura curricular do Curso de Biblioteconomia da Universidade Federal do Amazonas (UFAM) em relação às provas de concursos públicos da área aplicadas entre 2010 e 2013 no Estado do Amazonas. Sales et al. (2016) realizaram um estudo vinculado ao Programa de Educação Tutoria (PET) de Biblioteconomia da Universidade Federal do Cariri (UFCA), com intuito de mapear concursos públicos para o cargo de bibliotecário entre os anos de 2010 e 2015.

Pereira, Andretta e Hubner (2017) analisaram a matriz atual do Curso de Biblioteconomia da Universidade Federal de Rondônia (UNIR) e as exigências dos concursos das regiões Norte e Centro-Oeste do Brasil. Seabra (2017) investigou se e 
como os conteúdos das questões discursivas apresentadas nas provas de concursos brasileiros, realizados entre 2005 e 2017, são abordados nos planos de ensino e se fazem presentes na bibliografia dos programas de disciplinas do Curso de Biblioteconomia da Universidade Federal do Ceará (UFC).

Recentemente, Landgraf Neto (2020) finalizou seu trabalho de conclusão de curso e atualiza e complementa a pesquisa realizada por Oliveira (2015). O referido autor investigou as questões específicas encontradas nas provas de concurso do Estado do Paraná realizadas no ano de 2019 e as categorizou em conteúdos temáticos de acordo com as disciplinas da matriz curricular do Curso de Biblioteconomia da UEL que passou a vigorar em 2018. Conclui que o referido curso proporciona as bases fundamentais para que os estudantes possam se preparar de forma efetiva para as provas de concursos do Estado.

A partir da identificação e análise de tais pesquisas, verifica-se que há um padrão no perfil solicitado pelo mundo de trabalho, sobretudo, quando das habilidades e competências técnicas.

A seguir, apresentam-se os procedimentos metodológicos da pesquisa, que comparou os requisitos encontrados nos editais de concursos públicos e as habilidades proporcionadas a partir da matriz curricular de 2014 do curso de Biblioteconomia da UEL.

\section{PROCEDIMENTOS METODOLÓGICOS}

A tipologia da pesquisa é exploratória, cujo objetivo é o aprimoramento e/ou descoberta de ideias (GIL, 2002; MARCONI; LAKATOS, 2013). Quanto à abordagem do problema caracterizou-se como qualitativa, pois conforme afirma Gil (2002, p. 133) "[...] a análise qualitativa depende de muitos fatores tais como a natureza dos dados coletados, a extensão da amostra, os instrumentos de pesquisa e os pressupostos teóricos que nortearam a investigação [...]". Além disso, trabalhou-se com dados que não podem ser expressos numericamente e que dispensam o emprego de métodos estatísticos e probabilísticos.

O método da pesquisa foi o documental que, segundo Gil (2008, p. 51), “[...] vale-se de materiais que não receberam ainda um tratamento analítico, ou que ainda podem ser reelaborados de acordo com os objetivos da pesquisa." Neste trabalho foram analisados os editais de concurso das universidades estaduais do Paraná, 
sendo elas: Universidade Estadual de Londrina (UEL), Universidade Estadual de Maringá (UEM), Universidade Estadual do Norte do Paraná (UENP), Universidade Estadual de Ponta Grossa (UEPG), Universidade Estadual do Paraná (UNESPAR) e Universidade Estadual do Oeste do Paraná (UNIOESTE); as publicações de vagas no site InfoHome e a matriz curricular do curso de Biblioteconomia da UEL.

Desta forma, os resultados são apresentados com base na comparação da literatura analisada e da Análise Documental. Após a coleta, os dados foram analisados sob a ótica da Análise Categorial de Dados, influenciada pela Análise de Conteúdo de Laurence Bardin (2002). A análise de conteúdo trabalha com mensagens (comunicação) e seu objetivo "[...] é a manipulação de mensagens (conteúdo e expressão desse conteúdo), para evidenciar os indicadores que permitem inferir sobre uma outra realidade que não a da mensagem." (BARDIN, 2002, p. 46). Ao analisar os documentos escolhidos na pesquisa documental, os textos foram categorizados e agrupados de acordo com a similaridade e ocorrência dos discursos.

\section{RESULTADOS: DISCUSSÃO E APRESENTAÇÃO}

Inicialmente, apresenta-se o cenário dos últimos concursos realizados pelas universidades com edital para o cargo de bibliotecário, conforme quadro 1.

\begin{tabular}{|c|c|c|c|c|}
\hline \multicolumn{5}{|c|}{ Quadro 1 - Últimos concursos } \\
\hline IES & PERÍODO & CARGO & CARGA HORÁRIA & REMUNERACÃO \\
\hline UEL & 2013 & BIBLIOTECÁRIO & 40 horas semanais & $R \$ 2.674 .04$ \\
\hline UEM & 2014 & BIBLIOTECÁRIO & 40 horas semanais & $\mathrm{R} \$ 2.841,97$ \\
\hline UENP & 2018 & BIBLIOTECÁRIO & 40 horas semanais & $\mathrm{R} \$ 3.253,72$ \\
\hline UNESPAR & 2014 & BIBLIOTECÁRIO & 40 horas semanais & $R \$ 2.674,04$ \\
\hline UNIOESTE & 2013 & BIBLIOTECÁRIO & 40 horas semanais & $R \$ 2.511,07$ \\
\hline UEPG $^{1}$ & - & - & - & - \\
\hline
\end{tabular}

Fonte: Elaborado e atualizado a partir de Oliveira (2015).

Conforme o cenário apresentado no quadro 1 , todas as vagas ofertadas pelas instituições tinham como carga horária de trabalho 40 horas semanais. Como requisito básico (formal) todos editais exigiam a Graduação em Biblioteconomia e o Registro no Conselho Profissional.

\footnotetext{
${ }^{1}$ Não houve edital de concurso para o cargo de bibliotecário, apenas para o cargo de Técnico em Biblioteca em agosto de 2009.
} 
A partir da soma dos salários indicados nos editais dos concursos para bibliotecário, a média salarial ofertada pelas Instituições Estaduais de Ensino Superior (IEES) do Paraná é de $\mathrm{R} \$ 2.790,00$.

De acordo com o Sindicato dos Bibliotecários do Estado do Paraná (SINDIBPR), através da Convenção Coletiva de Trabalho 2018/2019 entre o SINDIB-PR e o Sindicato das Empresas de Serviços Contábeis e Assessoramento, Perícias, Informações e Pesquisas no Estado do Paraná (SESCAP) "[...] fica assegurado aos bibliotecários devidamente habilitados o salário de ingresso de $R \$ 2.891,00$ (dois mil oitocentos e noventa e um reais), para o divisor de 200 horas mensais, correspondendo à jornada de 40 horas semanais." (SINDIB, 2018).

Quanto às tarefas sumárias descritas nos editais, pode-se identificar uma similaridade entre elas, sendo que os editais da UEM, UENP, UNESPAR e UNIOESTE explicitaram "planejar; implementar; administrar e organizar bibliotecas e sistemas de acesso e recuperação de informação" e a UEL "planejar; administrar e organizar bibliotecas e sistemas de acesso e recuperação de informação". Constata-se que a única diferença entre as tarefas sumárias indicadas nos editais foi o termo "implementar", acrescido pelas demais quando comparado à UEL.

Além das tarefas sumárias, os editais também indicam a descrição detalhada das funções e competências e habilidades pessoais requeridas ao profissional. Para melhor visualização dessas descrições, apresenta-se a seguir um quadro com as habilidades e requisitos comuns aos editais.

Quadro 2 - Descrição detalhada, conhecimento específico e habilidades pessoais

\begin{tabular}{|c|c|}
\hline IES & DESCRIÇÃO DETALHADA \\
\hline $\begin{array}{c}\text { UEL } \\
\text { UEM } \\
\text { UENP } \\
\text { UNESPAR } \\
\text { UNIOESTE }\end{array}$ & $\begin{array}{l}\checkmark \text { Estabelecer, coordenar e executar a política de seleção e aferição do } \\
\text { material integrante das coleções de acervo, programando as prioridades } \\
\text { de aquisição dos bens patrimoniais para a operacionalização dos } \\
\text { serviços. } \\
\checkmark \text { Estruturar e efetivar a normalização e padronização dos serviços técnicos } \\
\text { de tratamento da informação fixando índices de eficiência, produtividade } \\
\text { e eficácia nas áreas operacionais da Biblioteconomia e ou Ciência da } \\
\text { Informação. } \\
\checkmark \text { Estruturar e executar a busca de dados e a pesquisa documental. } \\
\checkmark \text { Executar outras tarefas compatíveis com as exigências para o exercício } \\
\text { da função. } \\
\checkmark \text { Executar tarefas pertinentes à área de atuação, utilizando-se de } \\
\checkmark \text { equipamentos e programas de informática. } \\
\checkmark \text { Participar de programa de treinamento, quando convocado; } \\
\checkmark \text { Participar, conforme a política interna da Instituição, de projetos, cursos, }\end{array}$ \\
\hline
\end{tabular}




\begin{tabular}{|c|c|}
\hline & $\begin{array}{l}\checkmark \text { Planejar, implementar, coordenar, controlar e dirigir sistemas } \\
\text { biblioteconômicos e ou de informação e de unidades de serviços afins. } \\
\checkmark \text { Realizar estudos administrativos para o dimensionamento de } \\
\text { equipamentos, recursos humanos e layout das unidades da área } \\
\text { biblioteconômica e ou de informação. } \\
\checkmark \text { Realizar projetos relativos a estrutura de normalização da coleta, do } \\
\text { tratamento e da recuperação e da disseminação das informações } \\
\text { documentais em qualquer suporte. }\end{array}$ \\
\hline \multirow[b]{2}{*}{$\begin{array}{c}\text { UEL } \\
\text { UEM } \\
\text { UENP } \\
\text { UNESPAR } \\
\text { UNIOESTE }\end{array}$} & CONHECIMENTO ESPECÍFICO \\
\hline & $\begin{array}{l}\checkmark \text { Formação e Desenvolvimento de Coleções: seleção; aquisição; } \\
\text { avaliação e descarte. } \\
\checkmark \text { Planejamento, Organização e administração de bibliotecas e sistemas } \\
\text { de bibliotecas. } \\
\checkmark \text { Normas técnicas para área de documentação (ABNT): tipologia, funções } \\
\text { e aplicabilidade. } \\
\checkmark \text { Organização, Tratamento e Recuperação da Informação em Suportes } \\
\text { Diversos: representação descritiva de documentos: processos, } \\
\text { instrumentos e produtos; Código de Catalogação Anglo-Americano } \\
\text { (AACR 2); representação temática de documentos: processos, } \\
\text { instrumentos e produtos (Classificação Decimal de Dewey, } \\
\text { Classificação Decimal Universal); Resource Description and Access } \\
\text { (RDA); Indexação: coerência, qualidade da indexação e linguagens de } \\
\text { indexação; Formato MARC } 21 \text {; Catalogação cooperativa; Catálogos em } \\
\text { linha; Tratamento da informação em ambientes informatizados; } \\
\text { Conversão retrospectiva de registros catalográficos (importação e } \\
\text { exportação de dados). } \\
\checkmark \text { Tecnologias de informação: automação de serviços, bancos e bases de } \\
\text { dados, bibliotecas digitais e repositórios institucionais. }\end{array}$ \\
\hline \multirow[b]{2}{*}{$\begin{array}{c}\text { UEL } \\
\text { UEM } \\
\text { UENP } \\
\text { UNESPAR }\end{array}$} & HABILIDADES PESSOAIS \\
\hline & $\begin{array}{ll}\checkmark & \text { Agir com ética. } \\
\checkmark & \text { Capacidade de análise e síntese. } \\
\checkmark & \text { Capacidade de comunicação. } \\
\checkmark & \text { Capacidade de concentração. } \\
\checkmark & \text { Criatividade. } \\
\checkmark & \text { Iniciativa. } \\
\checkmark & \text { Manter-se atualizado. } \\
\checkmark & \text { Proatividade. } \\
\checkmark & \text { Senso de organização. } \\
\checkmark & \text { Trabalhar em equipe. } \\
\end{array}$ \\
\hline
\end{tabular}

Fonte: Elaborado e atualizado a partir de Oliveira (2015).

A descrição detalhada das funções é indicada nos editais com muita similaridade, sendo a redação e o conteúdo comuns a todos os consultados. Quanto à descrição dos conhecimentos específicos/área de atuação, foram identificadas muitas convergências e proximidades no conteúdo. No entanto, outras descrições quando ao conhecimento específico do bibliotecário também foram identificadas nos editais, porém alguns apresentaram divergência em relação aos demais, como: Biblioteconomia: legislação e ética profissional (UEL, UEM, UENP, UNIOESTE); 
Fundamentos Biblioteconomia e Documentação; Ciência da Informação: conceitos, teorias, metodologias, tipos de documentos e finalidade (UEM, UENP, UNIOESTE, UNESPAR); Serviço de Referência (UEL, UEM, UNESPAR); Língua inglesa: inglês instrumental (UEM).

As competências pessoais foram unânimes entre quatro dos cinco editais analisados, visto que somente a UNIOESTE não indica esse quesito. Ressalta-se, todavia, que tais traços se apresentam como genéricos e, portanto, poder-se-ia aplicálos a diferentes profissionais.

Com o intuito de responder ao principal objetivo do artigo, a seguir, apresentase um quadro comparativo que possibilita a compreensão do relacionamento entre as disciplinas que propõem determinadas habilidades aos estudantes, ou ao menos procuram isso, com os requisitos encontrados nos editais de concurso. O quadro 3 foi dividido em quatro colunas: A primeira foi composta a partir das sete áreas curriculares propostas pelos países do Mercosul em relação ao currículo de Biblioteconomia na última edição do Encontro de Diretores e Encontro de Docentes de Escolas de Biblioteconomia e Ciência da Informação do Mercosul (EBCIM), realizado em 2018 no Paraguai, sendo elas: 1) Fundamentos Teóricos da Biblioteconomia e Ciência da Informação; 2) Organização e Tratamento da Informação; 3) Recursos e Serviços de Informação; 4) Tecnologia da Informação; 5) Gestão da Informação; 6) Pesquisa em $\mathrm{BCl}$ e Áreas Afins; e 7) Práticas e Inovação Pedagógica. A segunda coluna contempla as disciplinas (matriz curricular do ano de 2014 do Curso de Biblioteconomia da UEL), que se enquadram em cada área curricular. Reconhece-se e alerta-se que, em muitos casos, uma mesma disciplina pode oferecer subsídios para diversas habilidades, no entanto, optou-se por classificar cada disciplina somente uma vez. A terceira coluna foi elaborada a partir da descrição detalhada e a última, quarta coluna, indica os conhecimentos específicos. 
Quadro 3 - Comparativo entre as áreas curriculares do EBCIM, disciplinas da matriz curricular 2014 com requisitos encontradas nos editais dos concursos.

\begin{tabular}{|c|c|c|c|}
\hline $\begin{array}{l}\text { Áreas curriculares } \\
\text { definidas pelos países do } \\
\text { Mercosul (2018/2019) }\end{array}$ & $\begin{array}{l}\text { Disciplinas matriz curricular do Curso de } \\
\text { Biblioteconomia UEL (2014) }\end{array}$ & Descrição detalhada & Conhecimento específico \\
\hline $\begin{array}{l}\text { 1) Fundamentos Teóricos } \\
\text { da Biblioteconomia e } \\
\text { Ciência da Informação e } \\
\text { áreas afins; }\end{array}$ & $\begin{array}{l}\text { - Introdução à Ciência da Informação } \\
\text { - Memória, Informação e Sociedade } \\
\text { - Comunicação e Informação } \\
\text { - Registros do Conhecimento } \\
\text { - Cultura Afro-Brasileira } \\
\text { - Ética e Atuação do Bibliotecário }\end{array}$ & NSA & $\begin{array}{l}\text { - Biblioteconomia: legislação e ética profissional. } \\
\text { - Fundamentos Biblioteconomia e Documentação; Ciência } \\
\text { da Informação: conceitos, teorias, metodologias, tipos de } \\
\text { documentos e finalidade. }\end{array}$ \\
\hline $\begin{array}{l}\text { 2) Organização e } \\
\text { Tratamento da Informação }\end{array}$ & $\begin{array}{l}\text { - Normalização Documentária } \\
\text { - Análise da Informação } \\
\text { - Organização da Informação e do Conhecimento } \\
\text { - Introdução à Catalogação } \\
\text { - Esquemas de Classificação } \\
\text { - Catalogação de Recursos Informacionais } \\
\text { - Vocabulários Controlados } \\
\text { - O Ciberespaço e os Índices Contemporâneos } \\
\text { - Indexação em Serviços de Informação } \\
\text { - Organização do Conhecimento em Ambientes } \\
\text { Digitais } \\
\text { - Comunicação Científica e Tecnológica } \\
\text { - Terminologia na Construção de Vocabulário } \\
\text { Controlado }\end{array}$ & $\begin{array}{l}\text { - Estruturar e efetivar a normalização e } \\
\text { padronização dos serviços técnicos de tratamento } \\
\text { da informação fixando índices de eficieincia, } \\
\text { produtividade e eficácia nas áreas operacionais da } \\
\text { Biblioteconomia e ou Ciência da Informação. }\end{array}$ & $\begin{array}{l}\text { - Normas técnicas para área de documentação (ABNT): } \\
\text { tipologia, funções e aplicabilidade. } \\
\text { - Organização, Tratamento e Recuperação da Informação } \\
\text { em Suportes Diversos: representação descritiva de } \\
\text { documentos: processos, instrumentos e produtos; Código } \\
\text { de Catalogação Anglo-Americano (AACR 2); } \\
\text { representação temática de documentos: processos, } \\
\text { instrumentos e produtos (Classificação Decimal de Dewey, } \\
\text { Classificação Decimal Universal); Resource Description } \\
\text { and Access (RDA); Indexação: coerência, qualidade da } \\
\text { indexação e linguagens de indexação; Formato MARC 21; } \\
\text { Catalogação cooperativa; Catálogos em linha; Tratamento } \\
\text { da informação em ambientes informatizados; Conversão } \\
\text { retrospectiva de registros catalográficos (importação e } \\
\text { exportação de dados) }\end{array}$ \\
\hline $\begin{array}{l}\text { 3) Recursos e Serviços de } \\
\text { Informação }\end{array}$ & $\begin{array}{l}\text { - Fontes Gerais de Informação } \\
\text { - Comportamento Informacional } \\
\text { - Fontes de Informação Bibliográficas } \\
\text { - Fontes de Informação Bibliográficas e } \\
\text { Especializadas } \\
\text { - Competência Informacional } \\
\text { - Centos Culturais, Bibliotecas Públicas e Escolares } \\
\text { - Serviço de Informação e Referência } \\
\text { - Mediação da Informação e do Conhecimento } \\
\text { - Leitura e Literatura Aplicada à Ciência da } \\
\text { Informação }\end{array}$ & $\begin{array}{l}\text { - Estruturar e executar a busca de dados e a } \\
\text { pesquisa documental. }\end{array}$ & - Serviço de Referência \\
\hline
\end{tabular}




\begin{tabular}{|c|c|c|c|}
\hline $\begin{array}{l}\text { 4) Tecnologia da } \\
\text { Informação }\end{array}$ & $\begin{array}{l}\text { - Plataformas Digitais Aplicadas à Ciência da } \\
\text { Informação } \\
\text { - Bases de Dados no Âmbito da Ciência da } \\
\text { Informação } \\
\text { - Preservação Digital } \\
\text { - Gestão da Automação } \\
\text { - Repositórios Digitais } \\
\text { - Arquitetura da Informação }\end{array}$ & $\begin{array}{l}\text { - Executar tarefas pertinentes à área de atuação, } \\
\text { utilizando-se de equipamentos e programas de } \\
\text { informática. } \\
\text { - Planejar, implementar, coordenar, controlar e } \\
\text { dirigir sistemas biblioteconômicos e ou de } \\
\text { informação e de unidades de serviços afins. } \\
\text { - Realizar estudos administrativos para o } \\
\text { dimensionamento de equipamentos, recursos } \\
\text { humanos e layout das unidades da área } \\
\text { biblioteconômica e ou de informação. }\end{array}$ & $\begin{array}{l}\text { - Tecnologias de informação: automação de serviços, } \\
\text { bancos e bases de dados, bibliotecas digitais e repositórios } \\
\text { institucionais. }\end{array}$ \\
\hline 5) Gestão da Informação & $\begin{array}{l}\text { - Preservação e Conservação de Acervos } \\
\text { Documentais } \\
\text { - Gestão de Unidades e Serviços de Informação } \\
\text { - Gestão e Desenvolvimento de Coleções } \\
\text { - Planejamento de Unidades e Serviços de } \\
\text { Informação } \\
\text { - Políticas de Informação }\end{array}$ & $\begin{array}{l}\text { - Estabelecer, coordenar e executar a política de } \\
\text { seleção e aferição do material integrante das } \\
\text { coleções de acervo, programando as prioridades de } \\
\text { aquisição dos bens patrimoniais para a } \\
\text { operacionalização dos serviços. }\end{array}$ & $\begin{array}{l}\text { - Formação e Desenvolvimento de Coleções: seleção; } \\
\text { aquisição; avaliação e descarte. } \\
\text { - Planejamento, Organização e administração de } \\
\text { bibliotecas e sistemas de bibliotecas }\end{array}$ \\
\hline $\begin{array}{l}\text { 6) Pesquisa em } \mathrm{BCl} \text { e } \\
\text { Áreas Afins }\end{array}$ & $\begin{array}{l}\text { - Produção de Texto } \\
\text { - Comunicação e expressão } \\
\text { - Língua Inglesa Aplicada à Ciência da Informação } \\
\text { - Estatística Aplicada à Ciência da Informação } \\
\text { - Perspectivas Metodológicas da Pesquisa } \\
\text { Científica } \\
\text { - Língua Espanhola Aplicada à Ciência da } \\
\text { Informação } \\
\text { - Pesquisa em Ciência da Informação e } \\
\text { Biblioteconomia } \\
\text { - Trabalho de Conclusão de Curso }\end{array}$ & $\begin{array}{l}\text { - Realizar projetos relativos a estrutura de } \\
\text { normalização da coleta, do tratamento e da } \\
\text { recuperação e da disseminação das informações } \\
\text { documentais em qualquer suporte. }\end{array}$ & - Língua inglesa: inglês instrumental. \\
\hline $\begin{array}{l}\text { 7) Práticas e Inovação } \\
\text { Pedagógica }\end{array}$ & $\begin{array}{l}\text { - Estágio Supervisionado } \\
\text { - Estágio Supervisionado em Atividades e/ou } \\
\text { Serviços de Informação } \\
\text { - Práticas de Estágio Supervisionadas }\end{array}$ & $\begin{array}{l}\text { - Executar outras tarefas compatíveis com as } \\
\text { exigências para o exercício da função. } \\
\text { - Participar de programa de treinamento, quando } \\
\text { convocado; } \\
\text { - Participar, conforme a política interna da } \\
\text { Instituição, de projetos, cursos, eventos, convênios } \\
\text { e programas de ensino, pesquisa e extensão. }\end{array}$ & NSA \\
\hline
\end{tabular}

Fonte: Elaborado e atualizado a partir de Oliveira (2015). 
O quadro 3 apresenta a relação das disciplinas através da matriz curricular de 2014, distribuídas nas sete áreas curriculares propostas pelos países do Mercosul em relação ao currículo de Biblioteconomia no ano de 2018, com as habilidades e exigências (descrição detalhada e conhecimento específico) encontradas nos editais dos concursos das universidades estaduais do Paraná para o cargo de bibliotecário. As "competências pessoais" como: Agir com ética, Capacidade de análise e síntese, Capacidade de comunicação, Capacidade de concentração, Criatividade, Iniciativa, Manter-se atualizado, Proatividade, Senso de organização, Trabalhar em equipe não foram expostas no quadro, porque se acredita que devem, ou ao menos deveriam, ser promovidas por todas as disciplinas e no curso em sua totalidade.

A análise se deu a partir dos títulos das disciplinas de acordo com a matriz curricular de 2014, não se atendo neste artigo às ementas e ao seu conteúdo programático. Reconhece-se que existem disciplinas que podem dar subsídio para diferentes habilidades e funções.

Com essa análise inicial verificou-se que, devido ao bibliotecário precisar de uma formação sólida, que possibilite o desenvolvimento de habilidades compatíveis com as exigências do mundo de trabalho, o Curso de Biblioteconomia da UEL tem possibilitado uma formação mais ampla e holística quando comparada aos requisitos exigidos pelos concursos analisados. É importante ressaltar, também, que a Universidade capacita de maneira técnica e instrumental os profissionais para suas ocupações no mundo do trabalho e procura desenvolver no sujeito diferentes habilidades (práticas e teóricas), que suscitem e possibilitem outros comportamentos e pensamentos, ou seja, não se visa apenas a formação de profissionais para o mundo de trabalho.

Destaca-se que as IES buscam no profissional características em que o comportamento e a capacidade de relação interpessoal esteja presente, e manter-se atualizado é fundamental não só para o bibliotecário, como para qualquer profissional. É através da educação continuada que o bibliotecário acompanha as mudanças que ocorrem tanto na academia, quanto no seu campo de trabalho. O crescimento profissional só ocorrerá, portanto, a partir do momento que busca e renova seus conhecimentos de forma contínua. 
Apenas com a formação do curso de Biblioteconomia não é possível atender na totalidade uma prova de concurso por exemplo, visto que além dos conhecimentos específicos existem questões de língua portuguesa, lógica, legislação etc. No entanto, o foco deste artigo não foi discutir esses elementos dos editais.

Outro aspecto que deve ser levado em conta é o fato da própria graduação em Biblioteconomia não dar conta de todas as especificações requeridas pelo mundo, ou seja, o estudante pode dominar um determinado conteúdo na teoria, mas não ter prática. A partir de conversas informais com estudantes de Biblioteconomia, há um consenso de que nas disciplinas de Gestão e Desenvolvimento de Coleções e aquelas voltadas ao tratamento, organização e representação da informação e do conhecimento, a carga horária prática é muito baixa; ainda que nos estágios supervisionados (obrigatórios e não-obrigatórios) eles têm contato com a prática. Acredita-se que esta não é uma realidade específica do curso de Biblioteconomia da UEL, mas também de outros cursos do Brasil, pois na maioria das vezes, os egressos procuram formação continuada e especialização num determinado ramo de atividade dentro da sua grande área de formação.

Constata-se, a priori, que as habilidades dos egressos formados a partir da matriz curricular de 2014 estão condizendo com as habilidades e requisitos requeridos pelos editais de concurso das universidades estaduais do Paraná para o cargo de bibliotecário. Isto não quer dizer que o bibliotecário não precise dar continuidade em seus estudos. Ressalta-se, ainda, que os resultados obtidos vão ao encontro daqueles apresentados por Lima (2007), Campos (2008), Kautzmann (2010), Faria (2015) e Moraes (2015) e já discutidos no referencial teórico deste artigo. Além disso, constatou-se que as vagas dos concursos públicos para bibliotecários de universidades estaduais paranaenses têm solicitado outras habilidades, que vão além das técnicas biblioteconômicas, conforme também foi apontado pelos autores supracitados.

É importante, também, que as universidades formadoras desenvolvam novas estratégias que permitam adequar os currículos e, por consequência, a matriz curricular do curso, pensando também nas exigências do mundo de trabalho. Levar isso em conta no momento da elaboração/reformulação/readequação de uma matriz curricular será uma maneira de mostrar a realidade que o mundo do trabalho 
apresenta e que os estudantes não têm a oportunidade de vivenciar. Essa experiência será valiosa para os estudantes conhecerem que existe um mundo competitivo antes mesmo de se formarem, e que é fundamental se adequar às exigências dele para o crescimento não apenas pessoal, mas também profissional.

\section{CONSIDERAÇÔES FINAIS}

Com base nos conteúdos encontrados na literatura verifica-se o quão importante é o bibliotecário se conscientizar de que, cada vez mais, o mundo de trabalho está exigindo mais destes profissionais, e com isso procure se atualizar. A educação continuada é a chave para o sucesso de qualquer profissional, por meio desse aperfeiçoamento e atualização o bibliotecário sempre terá lugar no mundo de trabalho.

Conclui-se que, de acordo com a comparação da matriz curricular de 2014 do curso de Biblioteconomia da UEL com os requisitos exigidos pelos editais de concurso das cinco universidades estaduais do Paraná, a formação dos egressos atende aos requisitos exigidos nos editais de concurso, mas isto não significa que possa se dispensar a educação continuada e capacitação depois de formado. Ele deve progredir e se aprimorar profissionalmente, pois quem trabalha com a informação tem um ambiente de trabalho favorável e o campo de atuação ampliado, além do que o mundo de trabalho está cada vez mais exigente, por isso a importância do bibliotecário sempre se atualizar, aprimorando suas habilidades e desenvolvendo diversas competências. Com tantos avanços tecnológicos, os egressos do curso de Biblioteconomia deverão ficar atentos às mudanças que ocorrem na sua área e procurar adequar seu perfil às novas competências inerentes ao seu fazer.

Este artigo apresentou um panorama específico, em relação à formação acadêmica do bibliotecário e a demanda das vagas de concurso em universidades estaduais do Paraná. Outra contribuição é a de que os resultados poderão servir de base para futuras readequações do curso de Biblioteconomia da UEL. Vale ressaltar que, no ano 2018 o curso da UEL realizou adequações no currículo, porém não houve alteração no seu Projeto Político Pedagógico. Vislumbra-se, também, a possibilidade de contribuir com outras escolas de Biblioteconomia do Brasil que estão em fase de reformulação e/ou adaptação em suas matrizes curriculares. 


\section{REFERÊNCIAS}

BARBOSA, M. L. A. Formação do bibliotecário: planejando e avaliando por parâmetros de competência. In: ENCONTRO NACIONAL DE PESQUISA EM PÓSGRADUAÇÃO EM CIÊNCIA DA INFORMAÇÃO, 15., 2014, Belo Horizonte. Anais eletrônicos[...] Belo Horizonte: UFMG, 2014. Disponível em: http://enancib2014.eci.ufmg.br/documentos/anais/anais-gt6. Acesso em: 17 jul. 2019.

BARDIN, L. Análise de conteúdo. Lisboa: Edições 70, 2002.

BIBLIO Eventos. Página do Facebook. 2015. Disponível em: www.facebook.com/biblioeventos. Acesso em: 11 mar. 2015.

BRASIL. Ministério da Educação. CNE/CES 492/2001. Diretrizes Curriculares Nacionais dos cursos de Filosofia, História, Geografia, Serviço Social, Comunicação Social, Ciências Sociais, Letras, Biblioteconomia, Arquivologia e Museologia. Diário Oficial [da] República Federativa do Brasil, Brasília, 9 jul. 2001, Seção 1, p. 50. Disponível em: http://portal.mec.gov.br/cne/arquivos/pdf/CES0492.pdf. Acesso em: 02 set. 2019.

CAMPOS, G. N. Características e perfil dos bibliotecários das bibliotecas de instituições de ensino superior privadas do distrito federal e as expectativas dos empregadores. 2008. 132f. Dissertação (Mestrado em Ciência da Informação) - Universidade de Brasília, Brasília, 2008. Disponível em:

http://repositorio.unb.br/bitstream/10482/1727/1/2008 GrazielleNoronhaCampos.pdf. Acesso em: 10 set. 2019.

CONTI, D. L; PINTO, M. C. C.; DAVOK, D. F. O perfil do bibliotecário empreendedor. Revista da Associação Catarinense de Bibliotecários - ACB: Biblioteconomia em Santa Catarina, Florianópolis, n. 1, v. 14, p, 27-46, jan./jul. 2009. Disponível em: https://revista.acbsc.org.br/racb/article/view/650. Acesso em: 02 ago. 2019.

CONVENÇÃO COLETIVA DE TRABALHO 2018/2019. Disponível em: http://www.sindib.pr.gov.br/arquivos/File/SESCAP 2018 2019.pdf. Acesso em: 15 ago. 2019.

ENCONTRO DE DIRETORES, 12.; ENCONTRO DE DOCENTES DE ESCOLAS DE BIBLIOTECONOMIA E CIÊNCIA DA INFORMAÇÃO DO MERCOSUL - EBCIM, 11., 2018. Disponível em:

https://sites.google.com/view/encuentroebcim2018py/ebcim?authuser=1. Acesso em: 15 ago. 2019.

FARIA, A. C. C. A inserção do bibliotecário no mercado de trabalho: fatores de influência e competências. 2015. 133 f. Dissertação (Mestrado em Ciência da Informação) - Universidade de Brasília, Brasília, 2015. Disponível em: http://repositorio.unb.br/handle/10482/18871. Acesso em: 08 set. 2019.

FIGUEIREDO, M. A. C.; SOUZA, R. R. Aspectos profissionais do bibliotecário. Revista Eletrônica de Biblioteconomia e Ciência da Informação, Florianópolis, n. 24, p. 10-31, 2. sem. 2007. Disponível em: 
https://periodicos.ufsc.br/index.php/eb/article/view/1518-2924.2007v12n24p10 Acesso em: 02 maio 2019.

GIL, A. C. Como elaborar projetos de pesquisa. 4. ed. São Paulo: Atlas, 2002.

GIL, A. C. Métodos e técnicas de pesquisa social. 6. ed. São Paulo: Atlas, 2008.

INFOHOME. 2018. Disponível em: http://www.ofaj.com.br/mercados.php. Acesso em: 09 ago. 2019.

KAUTZMANN, C. Competências dos bibliotecários de instituições de ensino superior: uma análise das ofertas de emprego. 2010. 78f. Trabalho de Conclusão de Curso (Graduação em Biblioteconomia) - Universidade Federal de Santa Catarina, Florianópolis, 2010. Disponível em:

https://repositorio.ufsc.br/bitstream/handle/123456789/120215/284486.pdf?sequence $=1$ \&isAllowed=y. Acesso em: 05 set. 2019.

LANDGRAF NETO, C. A formação do Bibliotecário na Universidade Estadual de Londrina frente as exigências em concursos públicos. 2020. 68f. Trabalho de Conclusão de Curso (Graduação em Biblioteconomia) - Universidade Estadual de Londrina, Londrina, 2020.

LIMA, L. J. O perfil do profissional da informação demandado pelo mercado de trabalho nas regiões sul e sudeste do Brasil. 2007. 42f. Trabalho de Conclusão de Curso (Graduação em Biblioteconomia) - Universidade Federal de Goiás, Faculdade de Comunicação E Biblioteconomia, Goiânia, 2007. Disponível em: https://repositorio.bc.ufg.br/bitstream/ri/4411/2/TCCG\%20-\%20BIBLIOTECONOMIALARA\%20DE\%20JESUS\%20LIMA.pdf. Acesso em: 08 set. 2019.

MARCONI, M. A.; LAKATOS, E. M. Técnicas de pesquisa: planejamento e execução de pesquisas, amostragens e técnicas de pesquisa, elaboração, análise e interpretação de dados. 7. ed. São Paulo: Atlas, 2003.

MIRANDA, A. Ciência da informação: teoria e metodologia de uma área em expansão. Brasília: Thesaurus, 2003.

MORAES, T. B. Análise do mercado de trabalho para o bibliotecário na região sul do Brasil, a partir de anúncios divulgados no site bibliovagas. 2015. 51f. Trabalho de Conclusão de Curso (Graduação em Biblioteconomia) - Universidade Federal do Rio Grande, Rio Grande, 2015. Disponível em:

http://repositorio.furg.br/bitstream/handle/1/7436/THAIN\%c3\%83\%20MORAES.pdf?s equence $=2$. Acesso em: 10 set. 2019.

OLIVEIRA, C. R. A formação e a atuação do bibliotecário no Paraná: uma análise das competências e habilidades requeridas pelas IEES/Pr em concursos públicos. 2015. 96f. Trabalho de Conclusão de Curso (Graduação em Biblioteconomia) Universidade Estadual de Londrina, Londrina, 2015.

PEREIRA, V. T.; ANDRETTA, P. I. S.; HUBNER, M. L. F. A nova grade do curso de Biblioteconomia da Universidade Federal de Rondônia e as exigências dos 
concursos das regiões norte e centro-oeste do Brasil. RBBD: Revista Brasileira de Biblioteconomia e Documentação, v. 13, p. 2374-2389, 2017. Disponível em: https://rbbd.febab.org.br/rbbd/article/view/951. Acesso em: 27 mar. 2020.

SALES, J. A.; SILVA, M. L. S.; BARROS, L. F.; PEREIRA, F. J. S.; MARTINS, G. K. Mercado de trabalho para bibliotecários no brasil: mapeamento dos concursos públicos entre os anos de 2010 e 2015. Biblionline, v. 12, n. 1, p. 26-37, 2016. Disponível em: http://hdl.handle.net/20.500.11959/brapci/16435. Acesso em: 12 jul. 2020.

SEABRA, N. H. N. Concursos públicos para o cargo de bibliotecário: análise comparativa das questões discursivas com os planos de ensino das disciplinas do Curso de Biblioteconomia da UFC. 2017. 67f. Monografia (Graduação em Biblioteconomia) - Universidade Federal do Ceará, Fortaleza, 2017. Disponível em: http://www.repositorio.ufc.br/handle/riufc/33242. Acesso em: 05 jul. 2020.

SILVEIRA, J. G. Reflexões sobre a profissão de bibliotecário. Boletim da Universidade Federal de Minas Gerais, ano 37, n. 1731, 2011. Disponível em: https://www.ufmg.br/boletim/bol1731/2.shtml Acesso em: 06 jun. 2019.

SIMOES, P. P.; MARQUEZ, S. O. M. Concursos públicos em biblioteconomia: estudo do Curso de Biblioteconomia da UFAM em relação a provas aplicadas no Amazonas. RBBD: Revista Brasileira de Biblioteconomia e Documentação, São Paulo, v. 11, p. 255-274, 2015. Disponível em: https://rbbd.febab.org.br/rbbd/article/view/509. Acesso em: 27 jun. 2020.

UNIVERSIDADE ESTADUAL DE LONDRINA - UEL. Pró-Reitoria de Recursos Humanos. Edital PRORH № 223/2013. Disponível em:

http://www.cops.uel.br/concursos/159 uel/edital 223 2013.pdf. Acesso em: 15 ago. 2019.

UNIVERSIDADE ESTADUAL DE MARINGÁ - UEM. Pró-Reitoria de Recursos Humanos e Assuntos Comunitários. Edital № 228/2014-PRH. Disponível em: http://www.drh.uem.br/res/Edital 2282014 prh.pdf. Acesso em: 14 ago. 2019.

UNIVERSIDADE ESTADUAL DO NORTE DO PARANÁ - UENP. Pró-Reitoria de Recursos Humanos. Edital № 112/2018-GR. Disponível em:

https://uenp.edu.br/prorh-concursos-testes/prorh-concurso-publico/concursoagente/concurso-agente-112-2018/11224-edital-112-2018-abertura-de-concursopara-contratacao-de-agentes-universitarios/file. Acesso: 14 ago. 2019.

UNIVERSIDADE ESTADUAL DO OESTE DO PARANÁ - UNIOESTE. Gabinete da Reitoria. Edital № 011/2013-GRE. Disponível em:

https://www5.unioeste.br/cogeps/arquivos/concursos/interno/2013/10cpagentes/001. pdf. Acesso em: 15 ago. 2019.

UNIVERSIDADE ESTADUAL DO PARANÁ - UNESPAR. Pró-Reitoria de Gestão de Pessoas e Desenvolvimento. Edital 001/2014. Disponível em: http://progesp.unespar.edu.br/menu-principal/concursos-publicos/concursopublico/edital-n-01-2014-unespar/edital-n-01-2014-edital-de-abertura-com- 
retificacoes-publicado-em-21-03-2014. Acesso em: 14 ago. 2019.

VALENTIM, M. L. P. Formação: competências e habilidades do profissional da informação. In: VALENTIM, M. L. P. Formação do profissional da informação.

São Paulo: Polis, 2002. p. 117-132. 